\title{
Organização de uma unidade de hemodiálise para o enfrentamento da Covid-19: Um relato de experiência
}

\author{
Organization of a hemodialysis unit to cope with the Covid-19: An experience report \\ Organización de una unidad de hemodiálisis para hacer frente a la Covid-19: Un informe de \\ experiencia
}

Recebido: 03/07/2021 | Revisado: 09/07/2021 | Aceito: 10/07/2021 | Publicado: 22/07/2021

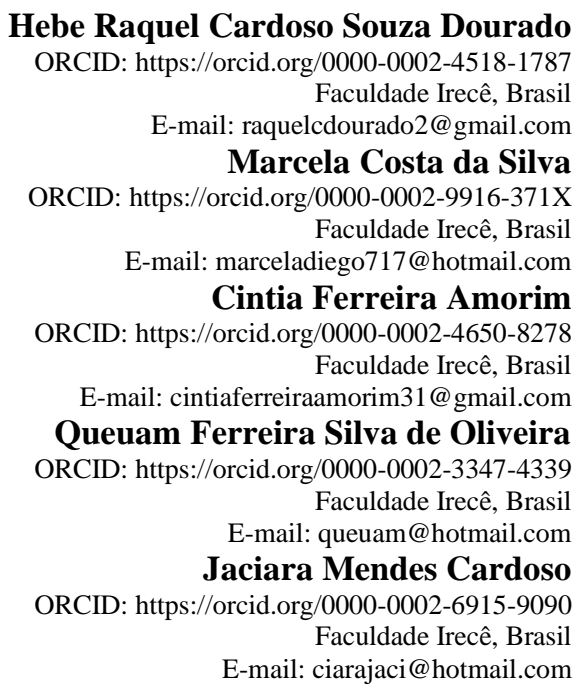

\begin{abstract}
Resumo
Objetivo: Descrever as experiências vivenciadas no processo de organização das atividades de uma clínica de hemodiálise para atender pacientes durante a pandemia da Covid-19. Metodologia: Trata-se de um relato de experiência com caráter descritivo dos aspectos vivenciados pelas autoras no processo de organização e treinamentos de uma unidade de terapia renal substitutiva em hemodiálise e nefrologia, em um município da região de saúde centro norte do estado da Bahia, para o enfrentamento da Covid-19 durante o estágio extracurricular de enfermagem nos meses de março a dezembro de 2020. Foi aplicada a metodologia da Problematização o Arco de Maguerez, a qual permite ao pesquisador identificar problemas do local de observação. Resultados: Observamos que os coordenadores do serviço analisaram minuciosamente as rotinas de atendimento da clínica, neste momento com o intuito de organizar o processo de trabalho para o enfrentamento da Covid-19, com o levantamento de ações que deveriam ser implementadas para evitar a contaminação pelo vírus durante as sessões de hemodiálise. As medidas preventivas foram adotadas com rigor, através de treinamentos com funcionários, pacientes e acompanhantes. A adesão dos envolvidos demonstrou grande responsabilidade, comprovada, nesse período de 230 pacientes, somente $13 \%$ tiveram a Covid-19. Considerações finais: Essa experiência em um contexto epidemiológico tão complexo contribuiu de forma significativa para a construção profissional dos envolvidos, agregando a importância de buscar informações científicas, experiência prática e desenvolvimento das habilidades de gestão dos serviços de saúde ainda na graduação.
\end{abstract}

Palavras-chave: Covid-19; Diálise renal; Enfermagem; Ensino.

\begin{abstract}
Objective: To describe the experiences lived in the process of organizing the activities of a hemodialysis clinic to care for patients during the Covid-19 pandemic. Methodology: This is an experience report with a descriptive character of the aspects experienced by the authors in the process of organization and training of a renal replacement therapy unit in hemodialysis and nephrology, in a municipality in the central north health region of the state of Bahia, for coping with Covid-19 during the extracurricular nursing internship from March to December 2020. The Maguerez Arch Problematization methodology was applied, which allows the researcher to identify problems in the place of observation. Results: We observed that the service coordinators carefully analyzed the clinic's care routines, at this time in order to organize the work process for coping with Covid-19, with a survey of actions that should be implemented to avoid contamination by the virus during hemodialysis sessions. Preventive measures were strictly adopted, through training with employees, patients and caregivers. The adherence of those involved showed great responsibility, proven,
\end{abstract}


in this period of 230 patients, only $13 \%$ had the Covid-19. Final considerations: This experience in such a complex epidemiological context contributed significantly to the professional construction of those involved, adding the importance of seeking scientific information, practical experience and development of management skills in health services while still in graduation.

Keywords: Covid-19; Renal dialysis; Nursing; Teaching.

\section{Resumen}

Objetivo: Describir las experiencias vividas en el proceso de organización de las actividades de una clínica de hemodiálisis para la atención de pacientes durante la pandemia de Covid-19. Metodología: Se trata de un relato de experiencia con carácter descriptivo de los aspectos vividos por los autores en el proceso de organización y formación de una unidad de terapia sustitutiva renal en hemodiálisis y nefrología, en un municipio de la región de salud centro norte del estado de Bahía. , para el afrontamiento del Covid-19 durante el internado extracurricular de enfermería de marzo a diciembre de 2020. Se aplicó la metodología de Problematización del Arco de Maguerez, que permite al investigador identificar problemas en el lugar de observación. Resultados: Observamos que los coordinadores de servicios analizaron cuidadosamente las rutinas de atención de la clínica, en este momento con el fin de organizar el proceso de trabajo para el afrontamiento del Covid-19, con un relevamiento de acciones que se deben implementar para evitar la contaminación por el virus durante las sesiones de hemodiálisis. Se adoptaron estrictamente medidas preventivas, a través de capacitaciones a empleados, pacientes y cuidadores. La adherencia de los involucrados mostró una gran responsabilidad, comprobada, en este período de 230 pacientes, solo el $13 \%$ tenía el Covid-19. Consideraciones finales: Esta experiencia en un contexto epidemiológico tan complejo ha contribuido significativamente a la construcción profesional de los involucrados, agregando la importancia de buscar información científica, experiencia práctica y desarrollar habilidades de gestión de servicios de salud en la etapa de egreso.

Palabras clave: Covid-19; Diálisis renal; Enfermería; Enseñanza.

\section{Introdução}

Em 12 de Março de 2020 a Organização Mundial de Saúde (OMS) declarou o surto de infecção pelo novo coronavírus SARS--COV-2 como uma pandemia, pois, havia mais de 125.000 casos relatados, e destes, mais de 40.000 foram diagnosticados em 118 países (Adhanom, et al., 2020). O foco inicial da pandemia foi na cidade de Wuhan na China e então estendido a outras cidades e províncias do país, e posteriormente a outros países da Ásia, Europa, África, América do Norte e América Latina (Rodriguez-Morales, 2020).

O SARS-COV-2 percorre principalmente em gotículas eliminadas na fala, tosse ou espirros e o contato com o vírus pode ocorrer de forma direta, de pessoa para pessoa, ou de forma indireta, quando encosta-se em superfícies e objetos contaminados (Aldarete, et al., 2020).

Os sintomas mais comuns da Covid-19 são febre, tosse, falta de ar, dor de cabeça, dor de garganta, fadiga, perda do paladar e/ou olfato, náuseas, vômitos e diarreia. A maioria dos casos desenvolve a forma leve e cerca de $14 \%$ a forma grave. Esta requer oxigenoterapia e internação hospitalar, sendo que 5\% necessitam de internação em unidade de terapia intensiva por desenvolverem síndrome da angústia respiratória aguda, sepse, choque séptico, insuficiência renal e falência de múltiplos órgãos (Osman, et al., 2020).

São considerados grupos de risco de agravamento da Covid-19 pessoas diagnosticadas com doenças crônicas, como diabetes Mellitus (DM) e hipertensão arterial sistêmica (HAS), asma, doença pulmonar obstrutiva crônica (DPOC), indivíduos acima de 60 anos, gestantes, entre outros. Existem estudos recém-publicados com dados sobre os grupos de risco ligados a maior mortalidade por Sars-Cov-2, citando as enfermidades hematológicas, incluindo anemia falciforme e talassemia, doença renal crônica e imunodepressão (Brasil, 2020).

Um dentre esses grupos é formado pelos pacientes em tratamento de hemodiálise, pois constituem uma população suscetível devido à idade avançada, sistema imunológico comprometido e coexistência de comorbidades importantes, como doenças cardiovasculares, diabetes mellitus entre outras, portanto, são mais propensos a desenvolverem doenças infecciosas graves do que a população em geral (Syed-Ahmed \& Narayanan, 2020).

Além disso, os pacientes em hemodiálise são expostos a um maior risco de contaminação do que o restante da população, pois, seu tratamento de rotina requer geralmente de três a quatro sessões de hemodiálise por semana. Portanto, todas as medidas 
para desacelerar e controlar a transmissão do vírus devem ser criteriosamente protocoladas e realizadas com todo rigor para esse grupo de vulneráveis (Ma Y, et al, 2020).

Foi publicado a experiência de uma unidade de hemodiálise em Wuhan, China, de um total de 230 pacientes em hemodiálise que relatou uma taxa de infecção por SARS--COV-2 de 16\% (371230) entre os pacientes e 12\% (4133) entre profissionais, o que demonstra uma alta taxa de transmissão do vírus neste público. Entretanto, a maioria dos pacientes apresentaram manifestações leves ou assintomáticas e a frequência dos sintomas foram: febre (11\%), fadiga (8\%) e tosse (3\%). A taxa de mortalidade da população total foi de 3\% (71230) (Ma Y, et al, 2020).

Fica evidente a necessidade de instituir um programa com recomendações e treinamentos específicos durante a pandemia da Covid-19, para pacientes em tratamento de hemodiálise, com medidas específicas durante o atendimento de filtração, nos ambientes compartilhados da clínica, no transporte e em casa, a fim de minimizar os riscos de contaminação, além de criar medidas de identificação precoce de casos suspeitos de infecção por SARS--COV-2, a fim de conter a propagação para outros pacientes e profissionais de saúde. Desta forma, objetiva-se descrever as experiências vivenciadas no processo de organização das atividades de uma clínica de hemodiálise para atender pacientes durante a pandemia da Covid-19.

\section{Metodologia}

Trata-se de um relato de experiência com caráter descritivo dos aspectos vivenciados pelas autoras no processo de organização e treinamentos de uma unidade de terapia renal substitutiva em hemodiálise e nefrologia, unidade satélite habilitada para o atendimento do Sistema Único de Saúde (SUS), em um município da região de saúde centro norte do estado da Bahia, para o enfrentamento da Covid-19 durante o estágio não obrigatório de enfermagem.

Duas discentes do nono período do curso de bacharelado em Enfermagem da Faculdade Irecê-FAI, realizaram o estágio não obrigatório no período de março a dezembro de 2020 de segunda a sexta-feira, 4 horas por dia, com o objetivo de vivenciar experiências, intercalando teoria e prática, para o crescimento profissional em uma clínica de hemodiálise, que atende 230 pacientes de segunda a sábado.

O relato aborda as experiências vivenciadas, o acompanhamento com o enfermeiro e suas demandas diárias, rotinas com a equipe, atendimento direto aos pacientes e o desenvolvimento de ações preventivas. Para descrição do relato foi aplicada a metodologia da Problematização o Arco de Maguerez a qual permite ao pesquisador identificar problemas do local de observação, com um método dividido em cinco etapas (Berbel \& Gamboa, 2012).

Na primeira etapa foi realizada a observação da unidade de hemodiálise, com o levantamento das dificuldades, carências e potencialidades da estrutura física, normas e rotinas da clínica, fluxograma de atendimento aos pacientes com doença renal crônica diante da situação de pandemia da Covid-19.

Em seguida foram delimitados os pontos chaves a serem estudados pelo tema e possíveis causas da existência dos problemas em razão da pandemia da Covid-19. Em reunião realizada pela equipe multiprofissional foram levantados alguns questionamentos sobre a organização e mudanças a serem introduzidas na rotina frente ao novo cenário epidemiológico, para posterior seguimento da terceira etapa de teorização do problema. Foi realizado o levantamento bibliográfico nas bases de dados Scielo (Scientific Electronic Library Online), Pubmed, a partir dos descritores de saúde ou palavras chave: diálise renal, infecções por coronavírus, enfermagem, prevenção de doenças. Os critérios de inclusão foram as publicações sobre Covid-19, medidas preventivas e hemodiálise entre o ano de 2019 a 2021. E como critério de exclusão os artigos com resumos indisponíveis nas bases de dados, com um total de 28 artigos, sendo desses, 21 inclusos.

$\mathrm{Na}$ quarta etapa foram estabelecidas hipóteses de solução para os problemas encontrados, com questionamentos, investigando todos os ângulos possíveis. E por último foi transposta as novas rotinas a realidade local. Foram realizados encontros, com o objetivo de capacitar e orientar equipe de profissionais e pacientes para o enfrentamento e contingenciamento 
da Covid-19. As temáticas abordadas nos encontros com os profissionais e pacientes foram: higiene correta das mãos, uso adequado dos equipamentos de proteção individual, orientações aos pacientes sobre o transporte, higienização correta dos alimentos e a conscientização da necessidade de evitar aglomerações.

\section{Resultados e Discussão}

Durante a vivência no estágio não obrigatório, foi possível observar uma grande preocupação em relação aos pacientes com doença renal crônica que fazem hemodiálise, visto que, com o aparecimento da Covid-19, as pessoas teriam que realizar o distanciamento social. Atitude complexa para executar nesse grupo de pacientes que necessitam realizar o tratamento por cerca de três vezes na semana, oriundos de bairros e municípios distintos. Com isso, verificou-se a necessidade de uma reestruturação do processo de trabalho, de modo a estabelecer medidas de prevenção para o enfrentamento da Covid-19 na unidade de Hemodiálise durante as sessões de tratamento. Essas estratégias instituídas na clínica foram de suma importância para o cuidado dessa população, haja vista que tem-se um fluxo de pacientes vindo de mais de 30 municípios diariamente.

A hemodiálise é um procedimento no qual o sangue é filtrado através de uma máquina. Esse procedimento retira do sangue substâncias prejudiciais à saúde, como o excesso de líquidos e eletrólitos em excesso, escórias eliminadas na urina, para assim, manter a homeostasia do corpo. As sessões são realizadas em clínicas especializadas ou em hospitais que tenham esse suporte. O processo de filtração é possível ocorrer através de um sistema extracorpóreo conectado a um acesso vascular. (SBN, 2020). As sessões de hemodiálise acontecem regularmente de três a quatro vezes por semana em local fechado, durante três a quatro horas, além de ser um procedimento invasivo, por meio de cateteres ou fístulas, se tornando uma possível fonte de infecção (Vega-Vega, 2020).

Além disso, o tratamento, sendo ele diálise peritoneal ou hemodiálise, deve ser mantido durante a pandemia o que envolve cuidados e procedimentos a serem adotados pelos pacientes, profissionais de saúde, gestores de unidades de hemodiálise e autoridades sanitárias (Abreu, 2020).

Dentre as ações de controle instituídas na clínica de estudo, destacamos: organização da entrada e saída dos pacientes em cada turno, com um distanciamento maior no momento de verificação do peso pré-diálise na balança, verificação da temperatura com termômetro digital de radiação, lavagem das mãos e braço da fístula com água e sabão, antissepsia completa da área da punção, reorganização dos assentos para realização da sessão de filtração, que foram demarcados de acordo com o município de origem dos pacientes, criação de sala de diálise exclusiva para atendimento individualizado para pacientes suspeitos ou assintomáticos, reforço das rotinas de higienização das mãos com álcool em gel 70\%, limpeza e desinfecção dos objetos e superfícies de uso frequente; disponibilização de máscara cirúrgica para os pacientes sintomáticos respiratório; e instituição de paramentação de contato respiratório para todos os profissionais de atendimento direto aos pacientes.

Em toda clínica foram colocados informativos sobre a lavagem correta das mãos, o uso frequente do álcool em gel, orientações sobre o distanciamento das pessoas nos espaços da clínica, uso correto da máscara, evitar viagens desnecessárias e aglomerações, limpeza correta dos alimentos, resguardar-se de compartilhar objetos pessoais com outras pessoas bem como sobre os sinais e sintomas da Covid-19. Foram fixados dispensadores de álcool em gel nas paredes e bancadas, além das padronizações anteriores, de modo a reforçar o acesso ao álcool. Em situações de sinais suspeitas para Covid-19, a pessoa era encaminhada para uma sala separada, para realização de uma triagem mais detalhada. Se o funcionário ou o paciente enquadrarse na definição de caso suspeito ele era orientado a entrar em contato com a Vigilância em Saúde do seu município para realizar o teste para Covid-19. Foram usadas para as capacitações presenciais, dinâmicas durante o atendimento e também envio de vídeos explicativos sobre as temáticas mencionadas acima. 
Tais atividades foram executadas com base nas recomendações da Sociedade Brasileira de Nefrologia-SBN (2020), como medidas para evitar a propagação do vírus. O envolvimento de toda população para a adesão consciente das medidas de prevenção da Covid-19 necessita de mudança dos hábitos individuais e coletivos, de forma rápida e rigorosa.

Experiências de países que adotaram medidas como distanciamento social e suspensão de aulas de forma precoce, tais como Singapura, Coreia do Sul e Japão, apontam que a implementação imediata dessas providências bem como o gerenciamento rigoroso dos casos e diagnósticos em massa influenciaram no curso da transmissibilidade, resultando num menor número de óbitos (Dong, et al, 2020).

Segundo a OMS (2020), a maioria das pessoas infectadas possuem sintomas leves e se recuperam, porém, algumas pessoas podem apresentar sintomas mais graves, dessa forma, a agência instituiu algumas recomendações a fim de minimizar a propagação dessa doença, como lavar as mãos com água e sabão ou higienizador a base de álcool, evitar tocar os olhos, nariz e boca, evitar sair de casa se não estiver se sentindo bem, se precisar sair de casa manter pelo menos 1 metro de distância de outras pessoas e procurar atendimento médico caso sinta sintomas como febre, tosse e dificuldade de respirar.

Foram reforçados durante os treinamentos para os profissionais da clínica a importância do uso de equipamentos de proteção individual, durante todo o turno de trabalho, assim como a colocação e retirada correta dos mesmos. A OMS instituiu o uso de máscara cirúrgica, seguir as boas práticas de uso, remoção e descarte, assim como higienizar adequadamente as mãos antes e após a remoção dos equipamentos de proteção individual. A recomendação salienta que o uso de máscaras deve ser sempre combinado com as outras medidas de proteção (protetor facial, avental, óculos de proteção, luvas de procedimento). Tais informações, foram realizadas um treinamento com uma médica infectologista, sobre as medidas de segurança, com todos os funcionários da unidade, sobre higienização das mãos com água e sabão e com solução alcoólica 70\%, bem como a abordagem com o paciente e a realização da limpeza e desinfecção da área que o paciente teve contato após cada processo dialítico.

Com base nesses dados observou-se que as medidas preventivas foram adotadas com rigor e responsabilidade dos envolvidos, visto o baixo número de notificações de infecção pela Covid-19. O que deve ser levado em consideração é que tanto os pacientes como os profissionais estavam susceptíveis ao risco da contaminação pela Covid-19 em outros ambientes que convivem. Nesse período, de 230 pacientes, somente 13\% tiveram a Covid-19.

Vale ressaltar que além do risco de contágio do vírus na clínica, as pessoas podem também se contaminar em ambientes diversos, como em casa, feiras livres, supermercados, ambientes de comercialização, de consumo, pelo fato desses lugares serem mal ventilados e com um fluxo grande de pessoas circulando, sendo necessário um cuidado a mais em relação ao cumprimento das medidas preventivas. (Abranches, et al, 2021).

Foi perceptível o empenho da equipe de profissionais em manter corretamente os protocolos instituídos. Sendo notório também a adesão das medidas pelos pacientes e acompanhantes, preocupados e cuidadosos quanto à proteção. Verificou-se a importância da educação em saúde como estratégia para reduzir as infecções e mortes pelo coronavírus.

Além do mais, a OMS recomenda que precisamos educar plenamente o público em geral sobre a seriedade do Covid19 e do seu papel na prevenção da propagação da doença (World Health Organization, 2020).

A Educação em Saúde além de contribuir para a formação da consciência crítica das pessoas a respeito da doença, ajuda a estimular a busca de medidas preventivas e ações tanto de forma individual quanto coletiva (Paes \& Paixão, 2016). Porém, nem todas as instituições conseguem o mesmo êxito nesse processo de adesão a essas medidas, gerando um entrave, devido a dificuldade de envolver o coletivo ou parte dele, como por exemplo realizar a quarentena e o distanciamento social, que apesar de adotadas pelos órgãos de saúde não possuem tanta adesão, ocasionando uma maior disseminação do vírus (Palacio \& Takenami, 2020).

A pandemia está instaurada e medidas profiláticas devem ser revistas e melhoradas a todo momento, evitando assim o adoecimento da população, em especial, a população renal, que constitui um público já bastante fragilizado. 
A alta circulação de pessoas e o aumento da propagação do vírus SARS-COV-2 têm propiciado o surgimento de 'variantes de preocupação' no Brasil, como é o caso da variante P1, descoberta em Manaus-AM. Dessa forma torna-se fundamental a adoção das medidas já apontadas, com foco para as medidas não farmacológicas, normas mais rigorosas de redução da circulação, de aglomerações e atividades não essenciais, bem como a primordialidade de aceleração da disponibilização de vacinas para o Programa Nacional de Imunizações (PNI), buscando contribuir para a diminuição de casos e a probabilidade de aparecimento de novas variantes (Lang, 2021).

\section{Considerações Finais}

Com base no estudo realizado verificamos a relevância da adesão das ações profiláticas e preventivas para o combate à disseminação e proliferação viral. Com ênfase no empenho da equipe de saúde em seguir corretamente o protocolo instituído pela instituição e a adesão dos pacientes e familiares, tendo como resultado uma baixa taxa de contaminação e mortalidade.

Tendo em vista, que o vírus foi recentemente descoberto e que ainda são poucos os estudos sobre a problemática, os protocolos e recomendações sofrem mudanças constantes. Enfatiza-se diante disso, a importância da manutenção de contínua atualização técnico científica. Vale ressaltar que o estudo em questão apresentou resultados eficazes no controle da contaminação pelo vírus com medidas preventivas de baixo custo e focadas na educação em saúde contínua.

Conclui-se que essa experiência em um contexto epidemiológico tão complexo contribuiu de forma significativa para a construção profissional dos envolvidos, agregando a importância de buscar informações científicas, experiência prática, vínculo com a equipe multiprofissional, pacientes e familiares. Possibilitou o desenvolvimento de um olhar direcionado na atividade de gestão do enfermeiro assim como seu papel como educador, acolhedor frente a situações inusitadas.

Como dito anteriormente a pandemia está instaurada e sujeita a mudanças, com o surgimento da vacina espera-se que os números venham a diminuir, o que causa um certo alívio à população, porém devido à grande circulação do vírus ocorre o surgimento de variantes, causando assim grande incerteza do desfecho dessa pandemia, visto que seu cenário está em constante mudança. Dessa forma torna-se necessário estudos e pesquisas atualizadas nessa área para que possamos acompanhar a evolução dessa pandemia e o que irá mudar no Brasil e no mundo após seu término.

\section{Referências}

Abranches, M. V., Oliveira, T. C., \& José, J. F. B. de S. (2021). A alimentação coletiva como espaço de saúde pública: os riscos sanitários e os desafios trazidos pela pandemia de Covid-19. Interface - Comunicação, Saúde, Educação, 25(1), e200654.

Abreu, A. P., Riella, M. C. R., \& Nascimento, M. M. (2020). A Sociedade Brasileira de Nefrologia e a pandemia pela Covid-19. Braz. J. Nephrol. 42, 1-3.

Adhanom T. WHO Director-General's opening remarks at the Mission briefing on COVID-19-12 (2020). Ginebra, Suiza: World Health Organization. https://www.who.int/dg/speeches/detail/who-director-general-s-opening-remarks-at-the-missionbriefing-on-covid-19---12-march-2020.

Aldarete, J. R. A. et al. (2020). Afinal, como o coronavírus reage no organismo? http://coro navirus.saude.mg.gov.br/blog/102-como-o-coronavirus-agenoorganismo.

Berbel, N.A.N. \& Gamboa, S.A.S. (2012). A metodologia da problematização com o Arco de Maguerez: uma perspectiva teórica e epistemológica. Filosofia e Educação (Online),

Brasil. Organização Pan-Americana de Saúde. Folha informativa COVID-19: Escritório da OPAS e da OMS no Brasil. https://www.paho.org/bra /index.php?option=com_content\&view=article \&id=6101:covid19\&Itemid=875\#risco.

Dong, E. Du, H. \& Gardner, L. (2020). An interactive web-based dashboard to track COVID-19 in real time: https://dx.doi. org/10.1016/S1473-3099(20)301201.

Lang, P. (2021). Fiocruz detecta mutação associada a variantes de preocupação no país. Agencia Fiocruz de Notícias. https://portal.fiocruz.br/noticia/fiocruzdetecta-mutacao-associada-variantes-de-preocupacao-no-pais.

Ma, Y., Diao, B., L. V. et al. (2019). Novel Coronavirus Disease in Hemodialysis (HD) Patients: Report from One HD Center in Wuhan, China.

Organização Mundial da Saúde. (2020). Folha informativa COVID-19 - Escritório da OPAS e da OMS no Brasil. https://www.paho.org/pt/covid19. 
Research, Society and Development, v. 10, n. 9, e10610917844, 2021

(CC BY 4.0) | ISSN 2525-3409 | DOI: http://dx.doi.org/10.33448/rsd-v10i9.17844

Organização Mundial de Saúde (OMS). (2020). Laboratory testing for coronavirus disease 2019 (COVID-19) in suspected human cases. Interim guidance. WHO/COVID-19/laboratory/2020.5, 19 https://www.who.int/publications-detail/laboratory-testing-for-2019-novel-coronavirus-in-suspected-human-cases20200117.

Organização Pan-Americana de Saúde (OPAS). (2021). OMS recomenda cuidados de acompanhamento para pessoas com COVID-19 e baixa dose de anticoagulantes para pacientes hospitalizados. https://www.paho.org/pt/noticias/26-1-2021-oms-recomenda-cuidados-acompanhamento-para-pessoas-comcovid-19-e-baixa-dose.

Osman, A. A., Daajani, M. M. \& Alsahafi, A. A. (2020). Re-positive coronavirus disease 2019 PCR test: could it be a reinfection? New Microbes and New Infections, 37, 100748,

Paes, C. C. D. C. \& Paixão, A. N. dos P. (2016). A Importância Da Abordagem Da Educação Em Saúde: Revisão De Literatura. Revista De Educação Da Universidade Federal Do Vale Do São Francisco, 6(11).

Palácio, M. A. V. \& Takenami, I. (2020). Em tempos de pandemia pela COVID-19: o desafio para a educação em saúde. Revista visa em debate sociedade, ciência tecnologia. https://visae mdebate.incqs.fiocruz.br/index.php/visaemdebate/article/view/1530/1147

Rodríguez-Morales, A., Bonila-Aldana, K., Balbin-Ramon, G. J., Rabaan, A. A., Sah, R., Paniz-Mondolfi, A. et al. (2020). History is repeating itself: probable zoonotic spillover as the cause of the 2019 novel coronavirus epidemic. Le Infezioni in Medicina. 2020,1:3-5.

SBN, Sociedade Brasileira de Nefrologia. (2020). Coronavírus: Eles Não Podem Ficar Em Casa. https://www.sbn.org.br/noticias/single/news/coronavirus-elesnao-podem-ficar-em-casa/.

SBN, Sociedade Brasileira de Nefrologia. (2020). O que é hemodiálise? https://www.sbn. org.br/orientacoes-etratamentos/tratamentos/hemodiálise.

Syed-Ahmed M., \& Narayanan M. (2020). Immune dysfunction and risk of infection in chronic kidney disease. AdvChronicKidneyDis $26:$ 8-15.

Vega-Veja, O., Arvizu-Hernández, M., Domínguez-Cherit, J. G., Sierra-Madero, J. \& Correa-Rotter, R. (2020). Prevención y control de lainfección por coronavirus SARS-CoV-2 (Covid-19) en unidades de hemodiálisis. Salud Publica 62:341-347.

World Health Organization. (2020). Infection Prevention and Control during Halth Care When Novel Coronavirus (NCOV) Infection Is Suspected. OMS. https://www.who.int/public ations/i/item/10665-331495. 